\title{
GeORG SimMel: As CidAdes, A Ruína E AS NOVÍSSIMAS METRÓPOLES
}

\author{
Carlos Fortuna* \\ (Faculdade de Economia / \\ Centro de Estudos Sociais da Universidade de Coimbra)
}

\section{Introdução}

Hoje, os grandes aglomerados urbanos são vistos como entidades carregadas de ambivalência nos seus sentidos e significados. Como há cem anos atrás, também as metrópoles e as megalópoles de hoje geram os sentimentos mais contraditórios e reproduzem imagens e configurações sociais diatópicas que ora parecem confirmar a emancipação dos indivíduos e grupos, ora ameaçam retirar-lhes autonomia e subordiná-los a perversos desígnios.

A "grande cidade" de Simmel está bem no centro dessas versões descoincidentes da moderna condição urbana. Ela reatualiza o velho aforismo medieval Stadtluft macht frei! ("Os ares da cidade libertam!") que prometia a livre afirmação individual e acalentava a esperança de um refúgio emancipatório dos sujeitos. À custa do desaparecimento da cultura provinciana das pequenas comunidades, a metrópole institui um novo modo de vida e abre caminho ao cosmopolitismo.

Os argumentos em torno da imanente democraticidade da cidade ou do reconhecimento da diversidade de movimentos feministas e neofeministas, de sincretismos religiosos, de movimentos antirracistas e neoétnicos, ativistas queer, entre outros (Lees, 2004), levam a admitir que a crise por que passam as metrópoles de hoje só poderá ser resolvida com mais metrópole, isto é, com o aprofundamento dos cenários de cosmopolitismo progressista.

No desenvolvimento dessas questões e numa aproximação à metrópole e à alegoria simmeliana da ruína, recorrerei a algumas das reflexões

*fortuna@fe.uc.pt

Philosophica, 42, Lisboa, 2013, pp. 107-123. 
filosóficas e estéticas de Simmel sobre a moderna condição urbana, começando pelo seu "A metrópole e a vida do espírito" (doravante referido como "A metrópole...") (Simmel, 1997). Celebrado por Louis Wirth como "o mais importante texto sociológico sobre a cidade" (Wirth, 1967: 219), este texto centenário ${ }^{1}$ assume uma condição especial quando tomado a par de outras reflexões estético-filosóficas de Simmel. Entre estas, pontuam as reflexões dedicadas à estética urbana veiculada pela interpretação que Simmel atribui às cidades históricas italianas (Roma, Florença e Veneza) e as considerações sobre o lugar da ruína na civilização ocidental (Simmel, 1959). É esta trilogia que agrega "A metrópole...", a análise estética de "Roma, Florença e Veneza" e a narrativa sobre "A ruína" que, no seu conjunto, tece uma relação própria de intertextualidade que faz ressaltar uma leitura simmeliana complexa sobre a vida urbana e os seus desafios e que aqui usarei como reflexão sobre a sua atualidade.

Pode parecer estranha essa associação de reflexões de natureza tão diversa como forma de refletir com Simmel sobre a atualidade da metrópole e da megalópole de hoje. Que ensinamentos poderemos retirar de Simmel com pertinência para a nossa compreensão de vida social tal como ela se desenrola hoje em Nova Iorque ou Tóquio, em São Paulo, Lagos ou Xangai? Onde poderemos recorrer ao pensamento de Simmel para clarificar o contexto de vida nestas cidades, sabendo que o autor não conheceu o crescimento pós-colonial descontrolado das grandes metrópoles, nem o ritmo estonteante do seu quotidiano, ou os efeitos indeléveis que novas modalidades de informação e comunicação têm sobre as sociabilidades urbanas do Norte e do Sul globais? Viverão essas cidades sociabilidades equiparáveis àquelas que Simmel inventariou para a Berlim de há um século atrás? Que semelhança enunciará a espetacularização da vida metropolitana atual com a estética das cidades históricas sobre que deteve parte importante da sua reflexão? Que níveis de indignação, ou de esperança, enunciam as atuais paisagens de privilégio e de destituição social que possam ser relidas à luz do pensamento Simmel? Caminhamos para um futuro da metrópole que é também o seu fim e a sua ruína?

Como argumentarei de seguida, a atualidade do pensamento de Simmel, como "clássico" da sociologia, encontra-se no valor heurístico que a sua releitura empresta à nossa capacidade de perguntar e não em

\footnotetext{
1 "A metrópole..." foi apresentado pela primeira vez em Dresden em 1903, numa conferência organizada pela Fundação Gehe com o intuito de celebrar a Primeira Exposição Municipal Alemã. Como outros eventos de impacto semelhante (por exemplo, a Exposição Comercial de Berlim de 1896), também a Exposição de Dresden reconheceria Berlim como moderna "cidade mundial", aberta às grandes inovações tecnológicas da época (transportes e comunicações) e capaz de cultivar o verdadeiro espírito de modernidade (Stewart, 2009: 2).
} 
qualquer capacidade espúria de oferecer respostas. Não é, portanto, Simmel e o seu pensamento que interpelamos aqui. É, sobretudo, a realidade metropolitana atual que queremos interpelar, na sua companhia.

\section{Die Großstädte e o presente eterno}

O contexto socioespacial da "grande cidade" de Berlim de meados do século $\mathrm{XIX}^{2}$ apresenta um conjunto de configurações de natureza semelhante às experiências banais do quotidiano urbano da atualidade. Dentre estas, uma das que mais prenderam a atenção de Simmel foi a dualidade individuação-sociação, que ganharia enorme centralidade na análise simmeliana de "A metrópole...". No entanto, Simmel dedica-se principalmente à análise psicossensorial das intersubjetividades e das interdependências dos sujeitos urbanos e secundariza aspetos institucionais e do funcionamento organizacional da vida urbana, incluindo os seus potenciais efeitos geradores de anomia pessoal (Rémy, 1995). ${ }^{3}$

${ }^{2}$ Diga-se de passagem que, em contraste com as megalópoles de hoje, a Berlim, como Großstädt que a linguagem canónica da sociologia urbana haveria de passar a designar por "metrópole", registava um pouco menos de 2 milhões de habitantes por volta de 1900. Era, no entanto, um desses universos urbanos que sofrera uma apreciável mudança cultural e política desde os princípios do século XVIII, quando não passava de uma pequena cidade (cerca de 50 mil habitantes) de retiro dos Hohenzollern. Em 1871, quando se tornou a capital do Reich, Berlim contaria já com mais de 800 mil habitantes. A informação disponível regista uma impressionante vitalidade urbana de Berlim nos princípios do século XX, quando Simmel escreveu "A metrópole...": 300 escolas, 90 hotéis, 80 hospitais, 31 bibliotecas, 14 museus, 400 salas de espetáculo, 100 editoras, 10 mil estudantes universitários e 300 jornais... (Jonas, 2008: 62). Por volta de 1900, Berlim sofreu significativas reformas nos meios de comunicação alimentados por ferrovias (20 estações), tramways e metropolitano (U-Bahn), que, a partir de 1902, com seis linhas em funcionamento, percorria uma extensão total de 38 quilómetros dentro da cidade, a que se juntaram as ligações periurbanas (S-Bahn), eletrificadas em 1913. Juntamente com esses recursos de mobilidade urbana regista-se, em 1914, a circulação de cerca de 7 mil veículos automóveis (idem; ibidem).

${ }^{3}$ A (in)comunicação entre sujeitos anónimos no contexto urbano moderno poderá caucionar a interpretação dos textos de Simmel como textos sobre a superficialidade da cidade e não sobre a sua estruturação social, económica e política. Mas tal como Isaac Joseph argumentou, pouco ganhamos em continuar a insistir na leveza das interpretações que se limitam à superficialidade das relações sociais (Joseph, 1988), do mesmo modo que é totalmente irrelevante acusar Simmel de não passar de um prosélito animador de tertúlias e círculos culturais restritos, usando uma escrita de estilo ensaístico e disperso. Acrescente-se ainda, sem que isso diminua o seu contributo intelectual, que Simmel teria aversão aos ambientes de pobreza e aos bairros proletários, do mesmo modo que desprezava a superficialidade e o exagero do entretenimento de massa alimentado pelos aglomerados urbanos de grande escala (Kapp, 2011: 442). 
"A metrópole..." de Simmel constitui, com efeito, um clamoroso exercício de subjetivação da experiência urbana, por meio da qual os sujeitos conferem sentido e procuram reagir em conformidade aos desafios impostos pelos fragmentos da sua inserção citadina. A subjetivação da experiência urbana conduz à mobilização radical dos sentidos e ao correspondente refúgio dos sujeitos na atitude blasé como instrumento de autodefesa e preservação da integridade pessoal, mental e relacional dos indivíduos que evitam, assim, cair numa "condição mental deplorável".

O que mais desejo assinalar é o facto de os atos simples e surpreendentes do quotidiano urbano das grandes cidades e megalópoles e o confronto com inusitadas figuras sociais surgirem, em Simmel, com um significado próprio que está muito além de simples detalhes inscritos no espaço e no tempo concretos da sua expressão material. A fenomenologia dessas circunstâncias avulsas do quotidiano, ou seja, os fragmentos $s u b$ species momentis da vida urbana, ao serem transpostos para uma realidade espaciotemporal distinta da pequena comunidade, configuram uma ordem social e cultural radicalmente nova. Esse é, em meu entender, o grande e intemporal contributo de "A metrópole...".

Nessa nova ordem sociocultural, aquilo que mais se destaca, por induzir o principal choque com os valores e comportamentos tradicionais dos contextos espaciais limitados, tende a ser relativizado por efeito da sua reprodutibilidade e permanência no tempo. O que parece ser momentâneo e repentino, na cidade moderna de Simmel, é, na sua essência, perene e duradouro, inscrevendo-se na configuração essencial da moderna condição urbana. A grande cidade da modernidade instaura assim uma nova sociação em que os mais singelos instantes de interação urbana se prolongam no tempo subjetivado dos sujeitos sob a forma de fragmentos sub species aeternitatis. É esta permanência e constância temporal do que parece efêmero que, de acordo com David Frisby, conferem ao nosso presente urbano a desconcertante qualidade de um "presente eterno", em que o que parece ser o choque originado pelo surgimento do novo é apenas o sinal da permanência do mesmo (Frisby, 1985).

Esse é o sentido que Simmel atribui, por exemplo, às figuras sociais do pobre, da prostituta, do estranho/estrangeiro, do aventureiro, mas também à coqueterie ou à moda, ou a outros tantos fragmentos do quotidiano urbano (Simmel, 1971). Não se trata de figuras historicamente situadas e seria erróneo interpretá-las desse modo, o que faria de Simmel um pensador de meros instantes da vida urbana. A densidade sociológica destes fragmentos emergentes da moderna cultura urbana decorre da sua permanência no tempo/espaço da cidade e do facto de se encontrarem inscritos na condição moderna que, sempre nova (ou renovada) acaba por permanecer, ceteris paribus, sempre a mesma. 
Este princípio da eternização do presente parece ter-se constituído na essência da metrópole de ontem e de hoje. Desde a sua enunciação em Simmel, constituiu-se em instrumento da decifração subjetiva da vida urbana, implicando a atitude de reserva individual dos sujeitos que, por essa via, modelam e adaptam constantemente as suas capacidades sensoriais ao ritmo da novidade urbana. Fazem-no de forma tão intensa e, dir-se-ia, competente, que parecem ser capazes de deixar de estranhar ou surpreender-se com a turbulenta mudança que presenciam na cidade, mostrando-se indiferentes perante aquilo que é novo na cidade para, paradoxalmente, se deixarem surpreender com mais frequência pelas reminiscências e as continuidades do passado.

\section{A metrópole e a ruína}

Interrogo-me sobre que continuidades poderão ter permanecido na passagem das grandes cidades do tempo de Simmel para as novíssimas metrópoles e megalópoles de hoje. A questão arrasta consigo uma inelutável reminiscência do modo como Walter Benjamin tratou a insinuação do passado no presente nas suas Teses sobre o Conceito de História. Benjamin argumenta que o ar de espanto do "anjo da história" resulta, não da incógnita do futuro da modernidade, mas antes do sobressalto provocado pelo rasto de decadência e ruína que vai ficando atrás de si (Benjamin, 1992: 249). Imagino por um instante que, qual "Angelus Novus", a metrópole se encontra ela própria em trânsito histórico, dirigindo-se, de marcha atrás, a um destino que desconhece. Revela, naturalmente, semelhante esgar de repulsa à medida que se dá conta da destruição e da ruína do passado que sustentam o futuro que a aguarda.

As considerações que farei sobre o jogo alegórico entre metrópole e ruína pressupõem que consideremos que a perceção da experiência urbana quotidiana é comandada pelas competências sensoriais dos sujeitos (Simmel, 1981; Füzesséry e Simay, 2008; Tonkiss, 2005). De modo semelhante à forma como trata da relação entre o elemento material e o elemento sensível, Simmel desenvolve os seus argumentos estético-filosóficos sobre a presença e o significado da ruína na modernidade. Fazendo recurso da tensão existente entre a díade espírito e natureza, ou se preferirmos, entre a esfera cultural e o elemento físico e material, em "A ruína" o autor começa por destacar o papel mediador da "arte da arquitetura" na resolução do conflito imanente entre natureza e espírito (ou cultura). Em contraste com a poesia, a pintura, a música ou a escultura, a intervenção da arquitetura distingue-se por ser capaz de modificar o ambiente natural e gerar um "equilíbrio singular" entre a vontade humana (digamos, a cultura) e a natureza que só os artistas, 
maxime os arquitetos, conseguem promover. Todavia, Simmel entende a "arte" da arquitetura como encontrando-se inscrita na lógica da finitude da vida material, pelo que estabelece um ordenamento temporário e frágil que só perdura "enquanto a construção se mantiver perfeita".

Antes subordinada ao espírito, a natureza dotada de "força brutal, corrosiva, demolidora e destrutiva", exibe a sua "revolta" e transfigura-se em ruína:

no instante em que a decadência destruir a unidade da forma, natureza e espírito voltam a separar-se novamente para revelar o seu estado original de acentuado antagonismo (Simmel, 1959: 260).

Convertida em ato prosaico de desabamento do edificado, aquela "rebelião" constitui-se na origem da ruína e permito-me considerá-la como expressão alegórica da conflitualidade urbana de todos os tempos. A ruína das cidades e grandes metrópoles de hoje interrompe assim a instável ordem dos opostos - espírito e natureza - e, superando a hegemonia do princípio da racionalidade humana e da suprema "arte" da arquitetura, é o desmoronamento (natural) do edificado que traduz a sua rendição perante a indomável força da natureza ${ }^{4}$.

Esta leitura não exclui a hipótese que Simmel coloca de a ruína poder expressar uma estética de harmonização de opostos da qual pode exalar um sentimento de paz e temperança (Fortuna, 1997). A alegoria simmeliana da ruína que apazigua a cidade e a reveste do "máximo encanto" (Simmel, 1959: 265) implica reconhecer que só a natureza pode originar tal processo. Ao invés, a decadência e a destruição da cidade que resultam da guerra urbana ou da incúria dos decisores e fazem irromper a ruína na cidade, apenas cultivam a fealdade e o tumulto.

Perguntamo-nos, portanto, se é universal essa possibilidade de rearmonização do mundo, através da estética que exala da presença da ruína nas metrópoles e cidades contemporâneas. Como derivada de um passado de conflito irresolvido, a presença da ruína nas metrópoles significa tensão e conflitualidade ou temperança e equilíbrio? Ou ambas as coisas, ainda que ideologicamente apropriadas por agentes diferenciados? Será que fortuitos visitantes das metrópoles valorizam uma delas e os seus conformados residentes outra? Por outras palavras, será que, para mantermos a ambivalência interpretativa de Simmel, os

\footnotetext{
${ }^{4}$ A alusão de Simmel a essa "rebelião" da natureza faz ressoar o "revanchismo" com que muitas cidades e metrópoles reagem a numerosas intervenções de enobrecimento e embelezamento urbano. Por serem efetivamente contra natura, muitas das soluções artísticas e arquitetónicas acabam por ser objeto de uma retomada da cidade que assim repõe os termos da sua condição anterior numa clamorosa denúncia dos limites da "gentrificação" (Smith, 1996).
} 
significados simbólicos da presença da ruína no espaço metropolitano são produzidos de modo desigual consoante os diversos contextos geo-culturais das metrópoles, por exemplo as do Sul e as do Norte globais?

\section{A estética simbólica das cidades e metrópoles}

Ao declarar que "a ruína é um local de vida de onde esta já desapareceu", Simmel desafia-nos a reconhecer a ambiguidade inerente à relação do passado com a modernidade: "a ruína cria a forma presente da vida passada" (Simmel, 1959: 261). Um possível desenvolvimento desta hipótese de eternização do passado no presente duradouro é o recurso à interpretação estética que Simmel produz a propósito das cidades históricas italianas de Roma, Florença e Veneza (Simmel, 2011).

Escritos em anos próximos ao surgimento de "A Metrópole...", os textos sobre "Roma" (1898), "Florença" (1906) e "Veneza" (1907) juntam-se, por direito próprio, ao corpus reflexivo de Simmel sobre a ruína, por um lado, e a vida urbana, por outro (Jonas, 1992; Fortuna, 2011a). Deste conjunto ressalta a clara confirmação do "panteísmo estético", de Simmel, que reconhece a beleza (da cidade) apenas como unidade das partes:

o mais forte atrativo da beleza consiste porventura no facto de ela constituir sempre a forma de elementos que, em si, são indiferentes e alheios à beleza e que só juntos adquirem valor estético. [...] [T]alvez que isto tenha a sua explicação naquela indiferença estética dos elementos e átomos do mundo, que só são portadores de beleza um em relação com o outro, e este apenas na relação com o primeiro, de modo que ela lhes é inerente, é certo, mas não é inerente a nenhum deles isoladamente (Simmel, 2011: 23).

Como "obra de arte" - tema tão insistentemente glosado posteriormente a Simmel (Ducret, 1989; Olsen, 1986) -, a cidade e a beleza que dela irradia envolvem uma outra unidade articulada de parcelas: a articulação da pluralidade dos seus tempos históricos. Esta é uma articulação a que "nenhum elemento, por mais arcaico, insólito ou inútil que seja, pode furtar-se" (idem: 25), o que explica como na interpretação de Simmel o passado se torne presente e assim seja "eterna" a cidade Roma - dada a particular unidade estética de ruínas e fragmentos. São profundas as consequências sociológicas que daqui derivam, com destaque para a "desorientação" dos sujeitos que veem interpelada a herança cultural que é parte integrante da sua moderna condição social:

\footnotetext{
${ }^{5}$ Para uma profunda análise do "panteísmo estético" de Simmel, deve-se consultar o estudo de Leopoldo Waizbort (2000: 75-112).
} 
[...] o indivíduo que toma consciência de si próprio no seio desta imagem de conjunto perde a posição que the foi concedida pelo seu círculo histórico-social estreito e fechado e vê-se de repente inserido e participante num sistema de valores imensamente variados, com o qual tem de se medir por assim dizer de modo objectivo (Simmel, 2011:27).

Certamente, no tempo de Simmel, o sistema de valores com que os sujeitos se defrontam na Roma diverge do que caracteriza as cidades congéneres de Florença ou Veneza. Para Armando Gnisci, com efeito, a differentia specifica da cidade de Roma reside no facto de as ruínas imprimirem uma marca singular na vida pública quotidiana da cidade, tomada como "sistema vivente das ruínas" (Gnisci, 2004)

Simmel retrata Florença como um exercício permanente de criação artística de que brota uma beleza estonteante - "[n]ão há talvez mais nenhuma cidade (...) [que] gere no observador de modo tão vincado uma impressão de obra de arte" (Simmel, 2011: 36) ${ }^{7}$ que inibe a "vingança" da natureza e o surgimento da ruína. Florença limita-se a confirmar a tensão trágica entre a natureza e o espírito.

Diferente de Florença, que mantém a tensão entre espírito e natureza, para Simmel, Veneza não passa de uma cidade labiríntica, feita de artificialidade e presunção. Pautada por jogos fantasiosos de máscaras e fachadismo, Veneza torna-se porventura pouco espiritual: "[n]ão existe provavelmente outra cidade cuja vida decorra tão integralmente à mesma velocidade", como ilustra a lenta deslocação das gôndolas que acompanham a cadência do caminhar das pessoas (idem, 45). "Demasiado humana", dir-se-ia, parfraseando Nietzsche, a ritmicidade da vida em Veneza "priva-nos das sacudidelas e dos estímulos que são necessários ao sentimento de plena realidade" (idem, 46), o que para Simmel contrasta

\footnotetext{
${ }^{6}$ Para Gnisci, esta incorporação praticamente irrepetível da ruína na regularidade da vida urbana de Roma é o sinal do modo como "a natureza não venceu o espírito" que, assim, permanece ativo e presente nos modos como usa e integra criativamente a ruína nas suas inesgotáveis ações de reenquadramento estético e urbano de escombros da era clássica (Gnisci, 2004).

${ }^{7}$ Simmel parece antecipar-se aqui aos efeitos de desorientação que a exposição à beleza pode causar e que foi recentemente tratada por "síndrome de Stendhal". A "síndrome de Stendhal" refere-se à disfunção somática - vertigens, taquicardia, alucinações - típica do romantismo que elogia a beleza e a perfeição e é tida como causadora de comoção até ao ponto de não poder ser suportada. Vivido por Stendhal durante a sua visita a Florença em 1817, esse choque "cultural" psicossomatizado obriga os pacientes a se afastarem para recuperarem o sentido de realidade. Tem sido objeto da investigação clínica da psiquiatra florentina Graziella Magherini (1989).
} 
de modo gritante com a vida intensa, agitada e veloz que é um dos fundamentos das grandes cidades do seu tempo, como repetidamente declara em "A metrópole...".

Por força da razão, passados mais de cem anos da análise de Simmel, Roma divergirá também do que caracteriza os ordenamentos sociais e as estruturas identitárias e de valores das grandes metrópoles e megalópoles deste milénio. Para desenvolver esta questão usarei um estratagema argumentativo que consiste no exercício de aplicar Simmel a Simmel. Tal significa tentar ser fiel ao princípio do que designarei de pantextualidade de Simmel que cauciona uma leitura transversal de todos os textos que assim surgem como fragmentos que, não obstante a sua autonomia relativa, se comunicam e ampliam o seu sentido, permitindo descortinar uma unidade argumentativa e de pensamento, neste caso centrada em torno da avaliação simmeliana do fenómeno urbano e metropolitano. Não são, portanto, textos isolados e circunscritos no seu significado, nem contributos delimitados espacial ou temporalmente (fragmentos sub species momentis).

\section{As novíssimas metrópoles: modernidade e ruína?}

Os escritos de Simmel que temos vindo a referir - a reflexão original de "A metrópole...", o ensaio sobre "A Ruína" e a série de reflexões sobre as cidades históricas italianas - oferecem, no seu conjunto, uma visão particular do moderno mundo urbano, atravessado por dilemas e conflitos de desfecho incerto. A principal distinção da conflitualidade que atravessa a metrópole de hoje, por comparação com as grandes cidades do tempo de Simmel, reside na natureza dos atores que a concretizam. A tensão entre espírito e natureza, ou entre homem e natureza, a que Simmel alude nas suas reflexões filosóficas sobre o ambiente urbano, é hoje, fruto dos avanços tecnológicos na construção e da crescente capacidade de dominação da natureza, fundamentalmente uma tensão conflitual entre humanos. A decadência, a destruição e a ruína a que a metrópole está hoje sujeita continuam a ser possíveis desfechos gerados pela "revolta" simmeliana da natureza contra o domínio que o espírito exerceu sobre ela. Contudo, o que mais pesa sobre esta metrópole contemporânea são os efeitos desestruturadores das novas convulsões e guerras que passaram a pontuar o ambiente de todo o mundo urbano. Por isso, ao contrário do que Simmel sugere, a ruína que vislumbramos nas cidades e metrópoles de hoje, não sendo fruto da ação subversiva da natureza, não pode irradiar beleza, nem suscitar sentimentos de equilíbrio ou temperança. A ação humana contida nas guerras e nos atentados urbanos dos nossos dias, ao reduzir, total ou parcialmente, as cidades a 
escombros, só causa repulsa e desolação. Renova o mau presságio que o Angelus Novus recolhia do espetáculo de devastação em que se fundava o seu trajeto rumo a um duvidoso progresso.

Além disso, admitindo que o futuro do conflito imanente à condição humana e urbana se manifesta de forma mais sensível no território da metrópole, é essencial reconhecer que as metrópoles não são iguais entre si, o que complexifica o quadro que estou a tentar esclarecer sobre a atualidade do mundo metropolitano de Simmel. A hipótese do desigual ritmo de sedimentação da urbanidade das metrópoles sugere que as as grandes cidades do Sul global vivem subordinadas a uma velocidade mais acentuada do que as suas congéneres do Norte. Isso mesmo pode ser comprovado fazendo recurso de um indicador pouco sofisiticado, mas elucidativo: o número de pessoas que fazem aumentar a cada hora a população de algumas das metrópoles e megacidades de hoje. Os resultados são manifestamente discrepantes. Num primeiro conjunto de grandes aglomerados urbanos, encontram-se, entre outros, os velozes aglomerados de Lagos (58 novos habitantes por hora), Daca (50), Mumbai (42), Deli e Jacarta (39) e Xangai (32). O ritmo deste desenrolar urbano mostra-se mais pausado em São Paulo (24 novos residentes por hora) e Cidade do México (23), e mostra-se pouco expressivo em Nova Iorque (12 novos habitantes) e Londres (6), sendo mesmo nulo em Berlim, um século decorrido sobre a sua reconhecida vitalidade ${ }^{8}$.

Estes números revelam, grosso modo, uma distribuição tripartida da cadência da metropolitanização e, por hipótese, traduzem condições desiguais de sustentabilidade sociocultural (equipamentos sociais), política (universalidade de direitos) e infraestrutural (habitação): 1) as metrópoles de primeira geração incluem os aglomerados com mais de um milhão de habitantes da primeira fase da urbanização capitalista do Norte global (Londres, Paris, Nova Iorque) na liderança, mas também Xangai; 2) a segunda geração de metrópoles refere-se à urbanização periférica e colonial dos finais do século XIX e perdura até meados do século XX (Mumbai, São Paulo, Cidade do México, Tóquio, entre outras); 3) por fim, as metrópoles de terceira geração que se referem, em geral, ao período do crescimento urbano posterior à descolonização e à independência de numerosas nações asiáticas e africanas, envolvendo o recente e acelerado crescimento da generalidade das "grandes cidades" do Sul global, como Jacarta, Daca, Lagos ou Guangzhou, entre outras.

Essa digressão permite verificar que, excetuado o caso de Xangai, as metrópoles de primeira geração estariam a viver um presente de resigna-

\footnotetext{
${ }^{8}$ A informação refere-se a cálculos feitos para o ano de 2015 e inclui, a um tempo, o crescimento natural e os números de imigrantes chegados (Burdett e Rode, 2007: 28-29).
} 
ção e apatia, dedicando grande parte da sua energia urbana à contemplação estética da sua história, da sua beleza e do seu poder. Seriam metrópoles blasé, entregues à autocontemplação e à esteticização urbanística. $\mathrm{O}$ inverso encontra-se nas intrépidas metrópoles da terceira geração, entregues a percorrer um percurso veloz de consolidação urbana, sem tempo nem condições para avaliar o seu passado. Não toleram a ruína que geram no atropelo do seu crescimento, nem reconhecem e menos combatem os efeitos anacrónicos produzidos pela dinâmica da sua imparável e informal urbanidade. Situadas algures nos antípodas da "demasiado humana" Veneza simmeliana, essas megacidades do Sul global projetam-se na velocidada alucinante de um futuro talvez demasiado (des)humano. Qual Angelus Novus reatualizado, podem suspeitar da virtude do que será o seu futuro, mas são impotentes para evitar o seu fluir.

As ritmicidades variáveis das metrópoles e megacidades estão associadas à expansão física dos seus territórios. As que mostram velocidades mais rápidas de viver o seu presente são também as que apresentam uma mancha ocupacional mais dispersa. Assim, também as metrópoles de terceira geração deixaram de poder ser absorvidas pelo olhar que, como dissemos, Simmel tanto celebrou como dispositivo de perceção do real. A metrópole e a megalópole tornaram-se, desse modo, excessivas e já só se deixam interpretar com o corpo todo. Mobilizamos todos os sentidos e tornamos sensíveis como nunca todas as expressões da vida pública (imagens, sons, cores e odores) (Fortuna, 2009), mas também biografias, memórias, indignações e medos (Hardoy e Satterthwaite, 1989; Seabrook, 1996; Davis, 2006; Neuwirth, 2006). Bem ao contrário do retrato que Simmel faz de Veneza, nas metrópoles de hoje não é possível viver sem as "sacudidelas e estímulos" físicos e simbólicos que são o "sal" do seu violento, desordenado e criativo quotidiano urbano.

A especulação fundiária é certamente uma das principais causas da ruína de muito dos grandes aglomerados urbanos de hoje, com destaque para a situação vivida no Sul global. A velocidade em que em algumas dessas cidades ocorrem as ações de renovação de velhos bairros e quarteirões da antiga cidade colonial, só é comparável à velocidade com que sucedem as ações de ocupação de velhos edifícios devolutos ou à construção informal de habitação por parte de recém-chegados moradores pobres. São dois lados da mesma moeda, de uma metrópole póscolonial que, todavia, vê multiplicarem-se as paisagens de ostentação e privilégio como marca de poder, ao lado dos cenários de destituição de direitos e implacável e impiedosa marginalização social.

$\mathrm{Na}$ linguagem incisiva que Giselle Beiguelman usa a propósito de São Paulo, dir-se-ia que se trata de metrópoles em estado de "permanente transição para lado nenhum" (Beiguelman, 2000). Mas transitar "para lado nenhum" parece ser também o destino de outras metrópoles de pri- 
meira geração. Por exemplo, a Nova Iorque que John dos Passos apelidou de "cidade de destruição", entregue desde sempre à reconversão de si mesma (Blachon, 2003), não deixa antever qualquer destino para a sua evolução. Poderá São Paulo equiparar-se a esta Nova Iorque, ou, para o efeito, a qualquer uma dessas metrópoles ricas do Norte rico, como a Berlim de Simmel, que com a sua febril reconfiguração estética e funcional de espaços sociais alteram constantemente, ou arrasam mesmo, os vínculos e as relações interpessoais de comunidades de memória e bairros históricos, devolvendo-lhes em troca fracos simulacros de urbanidade? Ou poderá São Paulo - metrópole de segunda geração na nomenclatura utilizada - ser equiparada às novíssimas metrópoles que vão recobrindo o planeta por inteiro, maxime, as metrópoles pobres do Sul pobre? Para muitos, dada a imparável velocidade em que vivem, as megalópoles como São Paulo pressagiam a ruína daquilo que nelas hoje é sinal de confiança num futuro de irrestrito sucesso (Figueira, 2004). Vão longe os tempos em que Denis Diderot assegurava ser necessário arruinar um monumento para que ele revelasse todo o seu esplendor (Diderot, 1995). Por isso, não creio que tenhamos de assistir à ruína física deliberada de marcas consagradas da "arte" da arquitetura de muitas destas megalópoles para que possamos admitir que, na sua caminhada para o futuro, deixarão sempre um qualquer escombro atrás de si, físico ou humano, material ou espiritual. Basta admitir que a guerra urbana em que muitas destas grandes cidades estão hoje envolvidas é, ela própria, o efeito paradoxal dos movimentos "antirruína" das ocupações e das lutas e movimentos pela emancipação social.

\section{Conclusão: as novíssimas metrópoles e a ruína}

A ideia de que as metrópoles mais jovens do mundo de hoje se encontram numa frenética transformação que não deixa sedimentar a relação dos indivíduos com o espaço e de uns com os outros é, sem dúvida, um sinal daqueles traços da modernidade urbana sobre que Simmel discorreu no seu ensaio seminal sobre a nova condição urbana. Por isso, em meu entendimento, o seu sofisticado pensamento filosófico sobre a metrópole constitui um recurso criativo indispensável para questionar a realidade urbana dos dias de hoje (Fortuna, 2011b). Sendo da máxima pertinência interpelá-lo acerca da complexa realidade urbana atual, não creio que seja legítimo pedir-lhe respostas. Podemos, isso sim, revisitar Simmel para tentarmos formular as perguntas mais adequadas à compreensão da realidade metropolitana que nos inquieta.

A Berlim de Simmel não é a São Paulo nem a Nova Iorque destes inícios do século XXI. Estas, por sua vez, comparadas aos maiores e mais 
dinâmicos aglomerados urbanos metropolitanos do mundo atual, parecem metrópoles antigas, cuja expansão é hoje limitada. As novíssimas metrópoles da terceira geração encontram-se noutras latitudes, em territórios da Ásia e da África. Saídas da ainda recente mudança pós-colonial, é nestas metrópoles que se encontram as mais graves disparidades sociopolíticas que afetam de modo sensível o quotidiano vivido dos seus habitantes. Para muitos milhões de excluídos destas novíssimas metrópoles, é enorme o desprendimento emocional em face dos espaços em que circulam e residem. Também não tem paralelo o grau da sua desvinculação e desenraizamento social, nem a condição económica aviltante que suportam (Seabrook, 2007). A condição social e política dos cidadãos rejeitados das metrópoles pobres faz destes milhões de destituídos indivíduos que cultivam, também eles, uma atitude blasé. Mas não são comparáveis aos blasés da "grande cidade" moderna e industrial da Europa de Simmel. Os pobres e os excluídos das novíssimas metrópoles do Sul global são expressão de um blasé de sentido invertido que, longe de ser uma opção, é o efeito direto da sua exclusão. Não escolheram viver a mesma indiferença deliberada que os berlinenses simmelianos ostentavam como estratégia de defesa pessoal e equilíbrio psico-emocional. Em vez disso, o blasé dos habitantes pobres das novíssimas metrópoles do Sul global reflete a indiferença forçada e a indignação contida de quem se vê desprovido de direitos e vive a submissão imposta por uma exploração sub-humana e uma indizível segregação.

Na linguagem usada ao longo do texto, esta condição de submissão representa uma expressão viva da ruína que se instala na caminhada das metrópoles para o futuro. A ruína é, portanto, uma condição imanente da grande cidade e da urbanidade que Simmel enunciou como expressão da modernidade. Essa relação íntima simmeliana do moderno com a ruína só pode ser compreendida na junção de contributos e fragmentos teórico-filosóficos sobre a estética da cidade a que se entregou o autor de "A metrópole...".

É legítimo perguntar sobre a atualidade desse pensamento. Seria como questionar sobre o que pode ter dito Simmel que possa interessar aos milhões de cidadãos metropolitanos pobres sujeitos a todo o tipo de "sacudidelas" nos espaços públicos de Mumbai, Daca, Lagos ou Xangai que esteja prescientemente enunciado na reflexão sobre o comportamento dos indivíduos nas ruas de Berlim de finais do século XIX, ou sobre a ruína como compromisso entre tempos múltiplos, ou sobre a bela e eterna Roma, ou a paisagem cultural florentina ou a desconcertante Veneza.

Aquilo que podemos arriscar dizer que o pensador alemão deixa como legado intelectual é a hipótese do surgimento da nova figuração social protagonizada pelo habitante destituído e pobre das grandes metrópoles do Sul global de hoje. Esse parece ser na verdade o ator social novo que ressaltaria da pesquisa sobre o que é moderno a que Simmel entregou a 
sua vida. Tal equivale a dizer que estamos chegados ao tempo em que a experiência da destituição generalizada dos seus habitantes tem de ser inscrita em traços indeléveis no trajeto futuro da urbanidade global. As implicações daí resultantes são várias e, por certo, envolvem uma revisão epistémica, cognitiva e política do que está a mudar na condição urbana global a partir das grandes cidades do Sul. Nessa mudança, para sermos fiéis ao julgamento de Simmel, há que contar com a inelutável produção de ruínas, mas também com as inegáveis lutas e movimentos antirruína.

O que Simmel poderá ter dito de relevante para esse novo ator social é que à semelhança do princípio da finitude e da transitoriedade das coisas que torna tenso e turbulento o ordenamento entre espírito (cultura) e natureza (matéria), também a relação política de desigualdade gritante existente no mundo de cidades em que vivemos pode ruir e gerar outras configurações. São tensos os termos do conflito entre humanos, uns com os outros e, por causa disso, em nosso redor tudo continuará a revelar sinais de existência efémera e transitória. A esperança para os espoliados das novíssimas metrópoles é possível, portanto. Faz parte do simmeliano "presente eterno", plástico e elástico, que continuaremos a viver nas Mumbais, Dacas, Lagos ou Xangais de todo o globo.

O que Simmel não disse, mas se adivinha, é que não poderemos ficar todos tolhidos, de um só golpe, pelo blasé das nossas más consciências e o desconforto das diferenças ilegítimas que o trajeto histórico da metrópole avoluma a cada instante. Algo deste hediondo espetáculo universal estaria a escapar à nossa atenção crítica. A visão ampla da totalidade das coisas implica que nenhum elemento, "por mais arcaico, insólito ou inútil que seja" (Simmel dixit), possa escapar a um dinâmico comprometimento com o futuro da vida urbana. Em consequência, a beleza do mundo como metrópole que se universaliza será aquilo que for a qualidade estética das interações que formos capazes de construir. Em consequência, talvez a estética redentora da metrópole do futuro resida na nossa disponibilidade para concretizar gradualmente uma coexistência intercultural pacífica, metrópole a metrópole, cidade a cidade, bairro a bairro, praça a praça, rua a rua e irmos forjando assim novas formas de viver e novos sentidos progressistas de cosmopolitismo.

\section{Referências bibliográficas}

Beiguelman, Giselle, (2000), «São Paulo: Main Street, South America», in Biswas, R. K. (Org.), Metropolis Now! Urban cultures in global cities, Viena/Nova Iorque: Springer-Verlag, pp. 180-193.

Benjamin, Walter, (1992) [1940], «Thesis on the philosophy of history», in Benjamin, W., Illuminations, org. e introd. de Hannah Arendt, Hammersmith: Fontana Press, pp. 245-255. 
Blachon, Anthony, (2003), «New York, the city of destruction (1890-1940)», in Clavaron, Y. e Dieterle, B. (Orgs.), La Mémoire des Villes/The Memory of Cities, Saint-Étienne: Publications de l'Université de Saint-Étienne, pp. 141-149.

Burdett, Ricky e Rode, Phillip, (2007), «The urban age project», in Burdett, R. e Sudjic, D. (Orgs.), Endless City, Nova Iorque: Phaidon Press, pp. 8-31.

Davis, Mike, (2006), Planeta Favela, São Paulo: Boitempo.

Diderot, Denis, (1995) [1767], Ruines et Paysages (Salon III), Paris: Hermann.

Ducret, André, (1989), «La ville comme œuvre d'art», Faces - Journal d'Architectures, No. 11, pp. 51-54.

Figueira, Jorge, (2004), «O duplo nome de Roma», in Marnoto, R. (Org.), Leonardo Express, Coimbra: Instituto de Estudos Italianos da Faculdade de Letras da Universidade de Coimbra e e|d|arq, Editorial do Departamento de Arquitetura da Faculdade de Ciências e Tecnologia da Universidade de Coimbra, pp. 85-89.

Fortuna, Carlos, (1997), «As cidades e as identidades: narrativas, patrimônio e memória», Revista Brasileira de Ciências Sociais, 33, pp. 127-141.

Fortuna, Carlos, (2009), «Cidade e urbanidade», in Fortuna, C. e Leite, R. P. (Orgs.), Plural de Cidade: novos léxicos urbanos, Coimbra: Almedina, pp. 83-97.

Fortuna, Carlos, (2011a), «Simmel e as cidades históricas italianas: uma introdução», in Simmel, G. Simmel: a cidade e a estética, org. e introd. de Carlos Fortuna, Coimbra: Imprensa da Universidade, pp. 11-17.

Fortuna, Carlos, (2011b), «Narrativas sobre a metrópole centenária: Simmel, Hessel e Seabrook», Cadernos Metrópole, Vol. 13, No. 26, pp. 379-393.

Frisby, David, (1985), Fragments of Modernity: theories of modernity in the work of Simmel, Kracauer and Benjamin, Cambridge: Polity Press.

Füzessery, Stéphane e Simay, Philippe, 2008, «Une théorie sensitive de la modernité», in Füzessery, S. e Simay, P. (Orgs.), Le Choc des Métropoles: Simmel, Kracauer, Benjamin, Paris: Éditions de l'Éclat, pp. 13-51.

Gnisci, Armando, (2004), «Roma como sistema de ruínas», in Marnoto, R. (Org.) Leonardo Express, Coimbra: Instituto de Estudos Italianos da Faculdade de Letras da Universidade de Coimbra e e|d|arq, Editorial do Departamento de Arquitetura da Faculdade de Ciências e Tecnologia da Universidade de Coimbra, pp. 61-83.

Hardoy, Jorge e Satterthwaite, David, (1989), Squatter Citizen: life in the urban third world, Londres: Earthscan.

Jonas, Stéphane, (1992), «Georg Simmel: sur l'esthétique des villes historiques italiennes», in Rammstadt, O. e Watier, P. (Orgs.), Georg Simmel et les Sciences Humaines, Paris: Méridiens Klincksieck, pp. 163-178.

Jonas, Stéphane, (2008), «Simmel et Berlin: de la grande ville à la métropole», in Füzessery, S. e Simay, P. (Orgs.), Le Choc des Métropoles: Simmel, Kracauer, Benjamin, Paris: Éditions de l'Éclat, pp. 55-80.

Joseph, Isaac, (1988), El Transeunte y el Espacio Urbano, Buenos Aires: Gedisa. Kapp, Silke, (2011), «De Simmel ao cotidiano na metrópole pós-urbana», Cadernos Metrópole, Vol. 13, No. 26, pp. 439-450. 
Lees, Loretta (org.), (2004), Emancipatory City: paradoxes and possibilities, Londres: Sage.

Magherini, Graziella, (1989), La Sindrome di Stendhal, Florença: Ponte Alle Grazie.

Neuwirth, Robert, (2006), Shadow Cities: a billion squatters, a new urban world, Nova Iorque: Routledge.

Olsen, Donald, (1986), The City as a Work of Art: London, Paris, Vienna, New Haven: Yale University Press.

Remy, Jean, (1995), «La grande ville et la petite ville: tension entre forme et sociabilité et forme esthétique chez Simmel», in Remy, J. (Org.), Georg Simmel: ville et modernité, Paris: L’Harmattan, pp. 61-89.

Seabrook, Jeremy, (1996), The Cities of the South: scenes from a developing world, Londres: Verso.

Seabrook, Jeremy, (2007), Cities, Ann Arbor: Pluto Press.

Simmel, Georg, (1959) [1911], «The ruin», in Simmel, G. et al, Essays on Sociology, Philosophy and Aesthetics, org. de Kurt H. Wollf, Nova Iorque: Harper, pp. 259-266. , (1971), On Individuality and Social Forms: selected writings, org. e introd. de Donald Levine, Chicago: The University of Chicago Press. , (1981) [1907], «Essai sur la sociologie des sens», in Simmel, G., Sociologie et Epistemologie, org. e introd. de Julien Freund, Paris: PUF, pp. 223-238.

, (1997) [1903], «A metrópole e a vida do espírito», in Fortuna, C. (Org.), Cidade, Cultura e Globalização, Oeiras: Celta, pp. 31-43.

—, (2011), Simmel: a cidade e a estética, org. e introd. de Carlos Fortuna, Coimbra: Imprensa da Universidade.

Smith, Neil, (1996), The New Urban Frontier: gentrification and the revanchist city, Londres/Nova Iorque: Routledge.

Stewart, Janet, (2009), Public Speaking in the City: debating and shaping the urban experience, Nova Iorque: Palgrave MacMillan.

Tonkiss, Fran, (2005), Space, the City and Social Theory: social relations and urban forms, Cambridge: Polity.

Waizbort, Leopold, (2007), «Simmel no Brasil», Dados - Revista de Ciências Sociais, Vol. 50, n. ${ }^{\circ} 1$, pp. 11-48.

Wirth, Louis, (1967), «A bibliography of the urban community», in Park, R. e Burgess, E. (Orgs.), The City: suggestions for investigation of human behavior in the urban environment, Chicago: University of Chicago Press, pp. 161-228. 


\title{
RESUMO
}

A validade científica de Simmel, enquanto "clássico" da Sociologia e do pensamento urbano da modernidade, encontra-se no valor heurístico que a sua leitura concede à nossa capacidade de perguntar. Neste artigo, em que refletimos sobre duas potentes alegorias simmelianas - a grande cidade e a ruína - não interpelamos Simmel, mas antes a realidade metropolitana atual que, na sua companhia, nos leva a questionar sobre como partilham o moderno e a ruína o mesmo presente eterno da urbanidade.

Palavras-chave: Simmel, novíssimas metrópoles, ruína, cultura urbana

\begin{abstract}
The scholarly strength of Simmel as a "classical" of sociology and modern urban thinking revolves around the heuristic value that his reading grants to our ability to inquiry. The article in which we reflect on two powerful simmelian allegories - the Großstädte and the ruin - does not question Simmel. Instead, under the guidance of the German intellectual, we question the current metropolitan reality and the way how modernity and ruin mix together and share the eternal present of urbanity.
\end{abstract}

Keywords: Simmel, newest metropolis, ruin, urban culture 